undergoes proteolytic processing that releases LL-37 from its carboxy terminus. Skin keratinocytes do not express hCAP-18/LL-37 under normal conditions, but only produce it in response to injury, inflammation or infection ${ }^{10}$. LL-37 has a strong affinity for lipopolysaccharide, and exhibits potent, broad-spectrum antibacterial activity that is affected little by the ionic concentrations found in extracellular fluids ${ }^{11}$.

Limited information exists about the signals, receptors and transduction mechanisms involved in the induction of LL-37 and other mammalian cathelicidins. The promoter region of the LL37 gene contains potential binding sites for acute-phase-response factors ${ }^{12}$. Lipopoly-saccharides, interleukin-6 and all-trans retinoic acid were reported to increase expression of two porcine cathelicidins ${ }^{13}$. Recently, the existence of murine and human Tolllike receptors (TLR-9) that recognize bacterial $C_{P}$ C DNA was reported ${ }^{14}$. The mechanism by which Shigella plasmids may interact with this receptor or its regulatory network to prevent hCAP-18 induction remains to be resolved.

If the ability of Shigella spp. to prevent hCAP-18/LL-37 production by epithelial cells resides on a plasmid, one wonders if similar plasmids exist in other bacteria or if the plasmid in Shigella bacteria can be transferred to them. Though these and many other questions remain to be addressed, the report by Islam, et al. ${ }^{1}$ opens a new area in the study of pathogenesis. Future findings are awaited with interest.

1. Islam, D. et al. Nature Med. 7, 180-185 (2001).

2. Nhieu, G.T. \& Sansonetti, P.J. Mechanism of Shigella entry into epithelial cells. Cum. Opin. Microbiol. 2, 51-55 (1999).

3. Rathman, M., de Lanerolle, P., Ohayon, $H_{\text {.4 }}$ Gounon, P. \& Sansonetti, P. Myosin light chain kinase plays an essential role in $S$. flexneri dissemination. J. Cell Sci.113, 3375-3386 (2000)

4. Gallo, R.L. et al. Identification of CRAMP, a cathelin-related antimicrobial peptide expressed in the embryonic and adult mouse. J. Biol. Chem. 272. 13088-13093 (1997).

5. Morrison, G.M., Davidson, D.J. \& Dorin, J.R. A novel mouse $\beta$ defensin, Defb2, which is upregulated in the airways by lipopolysaccharide. FEBS Lett. 442, 112-116 (1999).

6. Bals, R. et al. Mouse $\beta$-defensin 3 is an inducible antimicrobial peptide expressed in the epithelia of multiple organs. Infect. Immun. 67, 35423547 (1999).

7. O'Neil, D.A. et al. Expression and regulation of the human $\beta$-defensins hBD-1 and hBD-2 in intesti- nal epithelium. J. Immunol. 163، 6718-6724 (1999).

8. Harder, J., Bartels, J., Christophers, E. \& Schroder, J.M. Isolation and characterization of Human $[\beta]$ Defensin-3, a novel human inducible peptide antibiotic . J. Biol. Chem. (Nov 20, 2000, epub ahead of print)

9. Diamond, G., Kaiser, V., Rhodes, J., Russell, J.P. \& Bevins, C.L. Transcriptional regulation of B-defensin gene expression in tracheal epithelial cells. infect. Immun. 68, 113-119. (2000).

10. Frohm, M. et al. The expression of the gene coding for the antibacterial peptide LL-37 is induced in human keratinocytes during inflammatory disorders. J. Biol. Chem. 272, 15258-15263 (1997).

11. Turner, J., Cho, Y., Dinh, N.N., Waring, A.J. \& Lehrer, R.I. Activities of LL-37, a cathelin-associated antimicrobial peptide of human neutrophils. Antimicrab. Agts. Chemother. 42, 2206-2214 (1998).

12. Gudmundsson, G.H. et al. The human gene FALL39 and processing of the cathelin precursor to the antibacterial peptide LL-37 in granulocytes. Eur. J. Biochem . 238, 325-332 (1996).

13. Wu, H., Zhang, G., Minton, J.E., Ross, C.R. \& Blecha, F. Regulation of cathelicidin gene expression: induction by lipopolysaccharide, interleukin-6, retinoic acid, and Salmonella enterica serovar typhimurium infection. Infect. Immun. 68, 5552-5558 (2000).

14. Hemmi, H. et al. A Toll-like receptor recognizes bacterial DNA. Nature 408, 740-745 (2000).

\section{Department of Medicine}

UCLA School of Medicine

Los Angeles, Californía

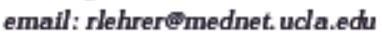

\title{
Noggin carves its niche
}

The process of neurogenesis, now recognized to be an ongoing process in adult mammalian brain, requires a specific molecular environment that neuroscientists are only beginning to understand. Neural stem cells are born in specialized regions of the adult brain such as the subventricular zone (SVZ). They then migrate along specific pathways into the olfactory bulb (where they differentiate into interneurons), as well as to cortical brain regions. Little is known about the signals present in brain regions such as the SVZ that create these special neurogenesis 'niches'. In the December issue of Neuron, Lim et al. (Neuron 28, 713-726) report that bone morphogenetic protein (BMP) and its natural antagonist Noggin, both well-characterized signaling molecules, are critical components of these local environmental effects. The authors show that the ependymal cells of the adult brain, which lie just adjacent to the SVZ, express Noggin, whereas the SVZ itself expresses BMPs and BMP receptors.

The authors use an in vitro model to study the mechanisms behind SVZ-de- rived cell differentiation. The picture shows a neurogenic colony descended from an adult SVZ precursor cell, cocultured with astrocytes. All the cells in this colony express the neuron-specific $\beta$ tubulin marker Tuj1 (red), and have incorporated BrdU (green), a nuclear marker of cell proliferation. The extensive area of double stain (yellow) indicates the proliferation of these neuronal precursors. Using this culture system, Lim et al. show that BMPs inhibit neurogenesis in a cell-autonomous manner, and instead induce the SVC cells to differentiate into glia. Addition of the BMP antagonist Noggin to SVC cultures, on the other hand, increased the birth of neurons by up to $50 \%$. The authors also used adenoviral vectors to direct the in vivo overexpression of BMP in the ependymal cells that lie adjacent to the SVZ. They found that this inappropriate expression of BMP reduced cell proliferation and halted SVZ neuroblast regeneration. Conversely, adenovirus-mediated expression of Noggin was able to activate neuronal proliferation of SVZ cells transplanted into a normally non-neuro-

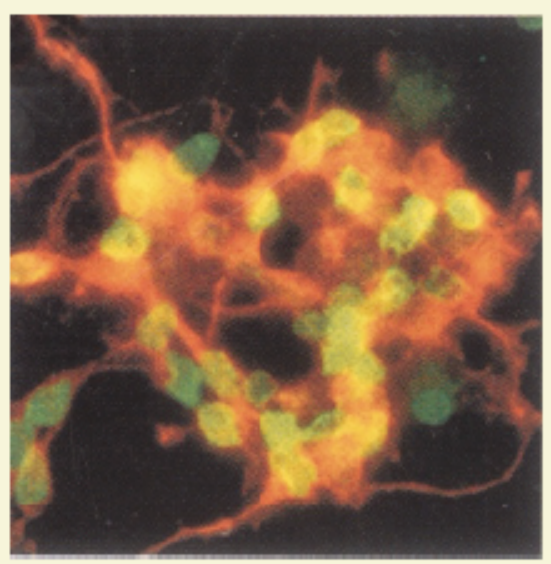

genic region of the brain.

The finding that BMP signaling is a key intrinsic regulator of glial versus neuronal fate in proliferating adult neurons is an important insight into the factors required for adult neurogenesis. These results also have clinical implications for the development of adult- or fetus-derived stem cells to treat neurodegenerative disease.

Charlotte Wang 